\title{
A pneumothorax? When to look twice and treat once
}

\author{
Muhammad Fahad Arshadd, ${ }^{1,2}$ Nasir Javed ${ }_{1}^{3}$ Lucy Peart, ${ }^{3}$ Nicholas Mallaband ${ }^{3}$
}

'Diabetes and Endocrine Department, Doncaster Royal Infirmary, Doncaster, South Yorkshire, UK

${ }^{2}$ Diabetes and Endocrine Department, Sheffield Teaching Hospitals, Sheffield, UK

${ }^{3}$ Acute Medicine Department, Doncaster Royal Infirmary, Doncaster, South Yorkshire, UK

\section{Correspondence to}

Dr Muhammad Fahad Arshad, dr.fahadarshad@live.com

Accepted 9 January 2018

\section{DESCRIPTION}

A large hiatus hernia in the thoracic cavity is rare but can result in respiratory symptoms and signs such as shortness of breath, unilateral reduced breath sounds and even respiratory failure. This condition, also known as gastrothorax, ${ }^{1}$ can sometimes be very challenging to diagnose due to its resemblance with pneumothorax. Few cases $^{2}{ }^{3}$ have been reported when gastrothorax has been mistakenly identified as pneumothorax and attempts have been made for aspiration of air, resulting in stomach perforation.

We present a case of a 57-year-old man who was referred to the on-call medical team by Accident

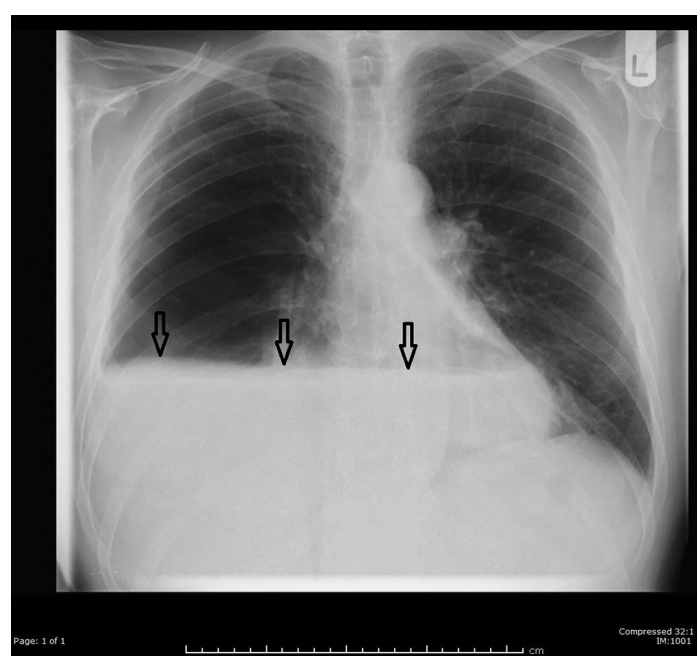

Figure 1 Chest X-ray. Arrows mark the air fluid level in the stomach.

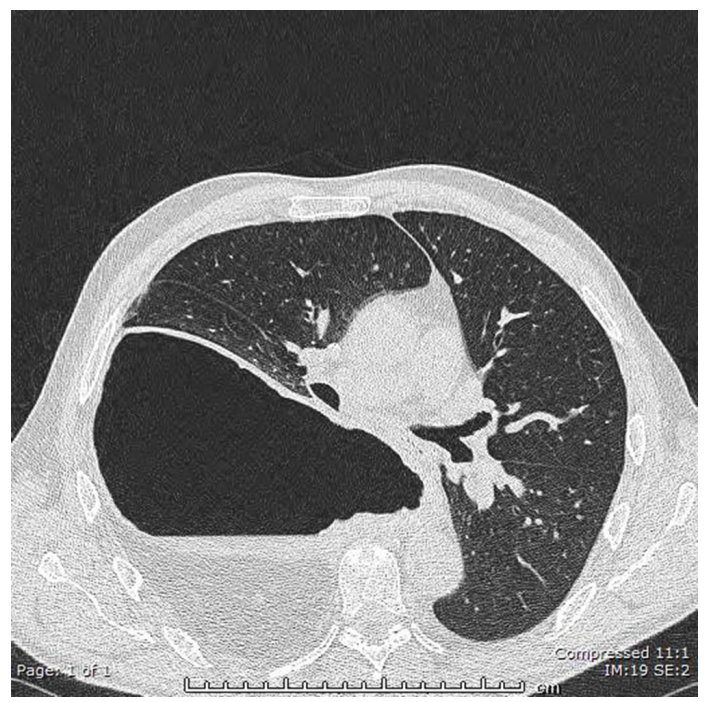

Figure 2 CT scan of the chest.
\& Emergency department with shortness of breath of 1 -week duration. When he was reviewed by the medical team, the clinical examination showed reduced breath sounds on the right side. He was gradually becoming more hypoxic requiring 35\% oxygen via venturi mask. An urgent chest X-ray was therefore performed, and the radiographer on call phoned the ward immediately and informed the medical team that there was a pneumothorax on the X-ray which potentially needs urgent chest tube insertion (figure 1).

The chest X-ray was reviewed by the medical team, but it was felt that the chest X-ray images were not typical of a pneumothorax or haemopneumothorax, and since the patient's oxygen saturations were stable at that point, a decision was made to perform an urgent CT scan of the chest first before draining the pneumothorax.

The CT scan showed a very large hiatus hernia with most of the stomach in the right hemithorax, with mediastinal shift, and no evidence of a pneumothorax (figure 2). A nasogastric tube was subsequently passed and approximately $750 \mathrm{~mL}$ of fluid

\section{Patient's perspective}

My wife found me unwell on returning home from a night shift. My general practitioner was called and telephoned for an ambulance. I was taken to Bassetlaw Hospital.

I was examined and given a chest X-ray. I was given very little information about my condition. I deteriorated overnight and was then given a CT scan. The images were sent to the thoracic team at Northern General Hospital, Sheffield. The team agreed to do the surgery that evening. I was taken straight to the hospital where the team were waiting. That is when I and my family found out how serious my condition was. I was taken straight to the theatre. I was there all night and all I can say is I feel very lucky to have had the surgeons Mr Edwards and Mr Wyman along with an amazing team.

My family and I can't thank them enough.

\section{Learning points}

- Gastrothorax can present with signs and symptoms resembling pneumothorax.

- Diagnosis of gastrothorax should be considered, especially in patients who have a prior history of a hiatus hernia. 
was aspirated. The patient was then referred and transferred to thoracic surgery for further management.

Contributors Concept: NJ and MFA. Writing the case and discussion: MFA and NJ. Images collection: NJ. Supervision and title: NM and LP. Title: LP

Funding This research received no specific grant from any funding agency in the public, commercial or not-for-profit sectors.

Competing interests None declared.

Patient consent Obtained.

Provenance and peer review Not commissioned; externally peer reviewed. (c) BMJ Publishing Group Ltd (unless otherwise stated in the text of the article) 2018. All rights reserved. No commercial use is permitted unless otherwise expressly granted.

\section{REFERENCES}

1 Chong CF, Lin YM, Chao CC, et al. Massive hiatal hernia masquerading as a tension pneumothorax. Am J Emerg Med 2007;25:226-8.

2 Ni KM, Watts JC. An important differential diagnosis of pneumothorax. Anaesthesia 2002:57:828-30

3 Zieren J, Enzweiler C, Müller JM. Tube thoracostomy complicates unrecognized diaphragmatic rupture. Thorac Cardiovasc Surg 1999;47:199-202.

Copyright 2017 BMJ Publishing Group. All rights reserved. For permission to reuse any of this content visit

http://group.bmj.com/group/rights-licensing/permissions.

BMJ Case Report Fellows may re-use this article for personal use and teaching without any further permission.

Become a Fellow of BMJ Case Reports today and you can:

- Submit as many cases as you like

Enjoy fast sympathetic peer review and rapid publication of accepted articles

- Access all the published articles

Re-use any of the published material for personal use and teaching without further permission

For information on Institutional Fellowships contact consortiasales@bmjgroup.com

Visit casereports.bmj.com for more articles like this and to become a Fellow 